\title{
Transcatheter aortic valve replacement, The Journal of Thoracic and Cardiovascular Surgery, and the evolution of clinical research in cardiothoracic surgery
}

\author{
Mario Gaudino, MD
}

From the Department of Cardiothoracic Surgery, Cornell Medicine, New York, NY.

Disclosures: Author has nothing to disclose with regard to commercial support.

Received for publication Dec 3, 2017; accepted for publication Dec 4, 2017; available ahead of print Jan 20, 2018.

Address for reprints: Mario Gaudino, MD, Department of Cardio-Thoracic Surgery, Weill Cornell Medicine, 525

E 68th St, New York, NY 10065 (E-mail: mfg9004@med.cornell.edu).

J Thorac Cardiovasc Surg 2018;155:1977

0022-5223/\$36.00

Copyright (C 2017 by The American Association for Thoracic Surgery

https://doi.org/10.1016/j.jtcvs.2017.12.021

In this issue of the Journal, Tam and colleagues ${ }^{1}$ present a cost-utility analysis of surgical versus transcatheter aortic valve replacement for aortic valve stenosis. The study has intrinsic limitations that the authors acknowledge, including the use of multiple and very different sources for data gathering and the derivation of key information from the Placement of Aortic Transcatheter Valves (PARTNER)-1 trial, whose generalizability can be strongly questioned. With all those limitations, however, the paper by Tam and colleagues ${ }^{1}$ remains an excellent piece of research and provides important information to the cardiothoracic surgery community.

I have no problem in admitting that the methodology used by Tam and colleagues ${ }^{1}$ is well above the level of my knowledge and that, when reading it, I had to ask for the help of my colleagues at the Department of Health Economics. While painstakingly trying to understand the details of Tam and colleagues" ${ }^{1}$ analysis, I went back to my first article published in the Journal. ${ }^{2}$ It was 1998 (and I was a resident). The paper was a case series of patients who had minimally invasive coronary bypass. The only statistics involved were descriptive and univariate analysis. There was no time to event or competing risk analysis, no control group, and no sample size calculation. With the current standards, it would never have been accepted by the Journal.

In the past 20 years, the evolution of clinical research in our field has been phenomenal. We all have learned the importance of applying correct methodology to our data and minimizing bias and confounders. Scientific journals and careful peer-review have been key in this evolution.

I have personally learned from the Journal's pages how to avoid comparing apples and oranges (or at least to try) ${ }^{3}$ and how (and when) to use matching techniques. The dedication and time-consuming efforts of reviewers and editors during the past 2 decades have immensely improved my

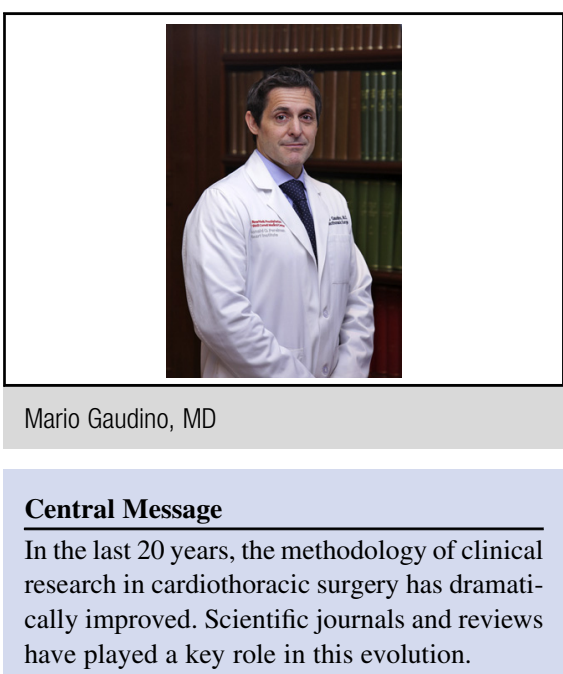

See Article page 1978.

methodologic knowledge and ability to produce goodquality papers. Statistical reviews have been particularly critical for me, and I'm convinced that there must be a particular place in the Heaven for those who have spent countless hours trying not only to improve my papers but also to unfold the principles of statistical techniques to surgeons like me.

The fact that a paper like the analysis of Tam and his colleagues ${ }^{1}$ came from a group of surgeons and is published in a surgical journal is a testament to the role of surgical scientific journals (the Journal in particular) and peer reviews in improving the quality of research and should make all of us (the present and past Editorial Board of the Journal in particular) proud of their job.

\section{References}

1. Tam DY, Hughes A, Fremes SE, Youn S, Hancock-Howard RL, Coyte PC Wijeysundera HC. A cost-utility analysis of transcatheter versus surgical aortic valve replacement for the treatment of aortic stenosis in the population with intermediate surgical risk. J Thorac Cardiovasc Surg. 2018;155:1978-88.

2. Possati G, Gaudino M, Alessandrini F, Zimarino M, Glieca F, Luciani N Systematic clinical and angiographic follow-up of patients undergoing minimally invasive coronary artery bypass. J Thorac Cardiovasc Surg. 1998;115: 785-90.

3. Blackstone EH. Comparing apples and oranges. J Thorac Cardiovasc Surg. 2002 $123: 8-15$. 